\title{
The Culture-Transmission Motive in Minorities: An Online Survey of Adolescents and Young Adults with an Immigrant Background in Germany
}

\author{
Irina Mchitarjan $^{1}$ and Rainer Reisenzein ${ }^{2}$ \\ ${ }^{1}$ Institute of Educational Science, University of Greifswald, Franz-Mehring-Straße 47, 17487 Greifswald, Germany \\ ${ }^{2}$ Institute of Psychology, University of Greifswald, Franz-Mehring-Straße 47, 17487 Greifswald, Germany \\ Correspondence should be addressed to Irina Mchitarjan; irina.mchitarjan@uni-greifswald.de
}

Received 4 August 2013; Accepted 22 August 2013

Academic Editors: G. Sideridis and S. Thoma

Copyright (C) 2013 I. Mchitarjan and R. Reisenzein. This is an open access article distributed under the Creative Commons Attribution License, which permits unrestricted use, distribution, and reproduction in any medium, provided the original work is properly cited.

\begin{abstract}
Central assumptions of a theory of cultural transmission in minorities proposed by the authors were tested in an online survey of adolescents and young adults with Russian and Turkish immigrant background in Germany $(N=55)$. The results support most hypotheses. In particular, evidence was obtained for the existence of the culture-transmission motive postulated by the theory: the appreciation of the culture of origin and the desire to maintain it and pass it on to the next generation. In addition, evidence was obtained for the anchoring of the culture-transmission motive in more basic motives, its relative stability, and its motivating function for pedagogical activities and wishes regarding cultural transmission, including the wish for culture-specific education in public schools.
\end{abstract}

\section{Introduction}

In recent years, in the wake of increasing international migration, the questions of how majority societies deal with linguistic and cultural, ethnic, and religious minorities and the related issue of cultural transmission in minorities have become focal topics of research in several branches of social science, including sociology, psychology, and educational science (e.g., [1-4]). Our interest in this paper is on the pedagogical aspects of cultural transmission in minorities: the educational activities of minorities in a foreign cultural environment and the policies of the majority towards them. Despite the importance of this topic, no theory specifically designed to explain cultural transmission in minorities has as yet been formulated. Instead, researchers have tried to apply existing theoretical frameworks, mostly taken from sociology, to explain the social phenomena in question; in particular, different versions of assimilation theory (e.g., [58]), transnationalism (e.g., [9]), and Bourdieu's [10] theory of cultural capital. However, in part simply because these theories were not originally developed to explain cultural transmission in minorities, they provide, in our view, only partial explanations. As an alternative, Mchitarjan and Reisenzein [11-13] recently proposed a theory of cultural transmission in minorities that is tailored to the social phenomena in question. This theory combines an actiontheoretical model, adopted from sociology and social psychology, with a theory of the cultural evolution of groups, and fills in this theoretical framework with a number of specific assumptions about the motives and strategies of majorities and minorities in cultural transmission situations. A central assumption of the theory is that sociocultural groups have a culture-transmission motive that has emerged in cultural evolution and is activated in migration situations. This plus other assumptions allow the proposed theory to explain several migration-related phenomena that pose difficulties to existing theories, in particular the frequently observed stability of cultural traits in immigrants and ethnic minorities (see, e.g., [13-15]).

Although several assumptions of the proposed theory of cultural transmission in minorities are at least indirectly supported by findings of existing historical and survey studies 
of migrants (e.g., [16-21]), so far the theory has not been subjected to a direct empirical test by confronting it with data specifically collected for this purpose. The study reported in this paper is a first attempt to provide such a test. Before describing the hypotheses, we give a summary of the theory.

\section{A Theory of Cultural Transmission in Minorities}

The focus of the theory of cultural transmission in minorities proposed by Mchitarjan and Reisenzein [11-13] is the interaction between sociocultural majorities and minorities in the area of education: the educational activities of minorities undertaken for the purpose of maintaining their culture, and the educational policies of the majority towards them. (In accordance with a common definition of ethnic minorities in contemporary social science (see, e.g., [22]), minorities are conceptualized as low-power subgroups of a society that have or claim a cultural [ethnic, linguistic, religious] identity.) The explanation of these social phenomena by the theory of cultural transmission in minorities targets two connected levels of explanation: (a) the level of the proximate psychological mechanisms that underlie the actions of minorities and majorities in cultural transmission situations and (b) the level of the distal, cultural-evolutionary processes that have resulted in the emergence of these mechanisms. Corresponding to these two levels of explanation, the theory comprises two components: (a) an action-theoretical model of minority-majority interactions in the domain of education and (b) a theory of the evolution of sociocultural groups, which provides an enhanced understanding of the basic goals and strategies of minorities and majorities in cultural transmission situations.

2.1. An Action-Theoretical Model of Cultural Transmission Processes. The conceptual foundation of the first component of the theory-the action-theoretical model of cultural transmission processes-is a simple model of group interaction, whose core is a theory of boundedly rational action of individual actors (see e.g., [23-25]). To apply this theory to groups, we make the simplifying assumption that group interactions can be modeled as analogous to interactions between individuals. Accordingly, we conceptualize the minority and the majority as two social actors who are equipped with particular beliefs, desires (goals), and resources (power, skills, material resources, etc.) and who attempt, by and large in a rational fashion, to achieve their goals in the area of education in a given historical situation. As in the case of the interaction between individuals, we assume that the actions of the minority and majority and their success or failure are determined by three groups of factors (see e.g., [26]): (1) motivational factors, that is, the motives, desires, or goals of the minority and majority, (2) epistemic factors, in particular the beliefs of the minority and majority about their ability to realize their respective goals by particular actions, and (3) the objective situational constraints that apply to both actors, which can be either conducive or obstructive to their goals (e.g., knowledge, skills, financial resources, laws, and domestic and international political conditions).

In the theory of cultural transmission in minorities, this general action-theoretical model of group interaction is elaborated by supplementing it with additional assumptions. The most important of these is the assumption that sociocultural groups have, in addition to their other motives-in particular, the desires to preserve and increase their resources and their power $[10,27]-$ a culture-transmission motive: A special appreciation of their culture of origin and the desire to preserve it and transmit it to the next generation.

The assumption that groups have a culture-transmission motive is a central point that distinguishes the present theory from other theoretical accounts in the field of acculturation and migration research. For example, Esser's ([6]; see also $[24,28]$ ) assimilation-theoretic account assumes (following Lindenberg [29], who in turn refers to Smith, [30]) that migrants' decision to integrate or not is based on but two motives: the desire for physical well being, and the desire for social approval (see also, $[24,28]$ ). In our view, this actor model is too simple. In agreement with more recent empirical-psychological (e.g., [31, 32]) and evolutionary (e.g., [33]) approaches to motivation, we believe that the motives of humans are more diverse. In particular, we assume that, in addition to their other motives, social actors typically also have a culture-transmission motive. Although we assume that the culture-transmission motive is acquired during socialization and, therefore, derived from more fundamental motives, we assume that it is functionally autonomous in Allport's [34] sense, and hence, is an independent source of motivation for action. Therefore, explanations of migration-related phenomena that fail to consider the culture-transmission motive are at least incomplete.

To prevent misunderstandings, we emphasize that assuming a culture-transmission motive implies neither a "primordial" nor an "essentialist" view of culture (for discussions, see e.g., $[1,35,36])$. In fact, according to our theory, culture is "socially constructed" in at least three ways: it is socially transmitted; its core components (including norms and values, language, and even the culture-transmission motive itself) are products of cultural evolution; and it contains, in addition to objectifiable elements such as language and norms, important subjective elements including the group's selfdefinition. Furthermore, postulating a culture-transmission motive in a group does not imply that the motive is necessarily strong in all group members; rather, because the motive is transmitted through socialization practices that are not identical for everybody, individual differences in the strength of the culture-transmission motive are to be expected. Finally, by postulating a culture-transmission motive, we do not mean to imply that this motive necessarily has the form of an explicit desire to "maintain and disseminate one's culture;" it may also (and perhaps typically does) consist of a plurality of more specific wishes for the preservation and transmission of particular cultural elements (e.g., language, or particular behavior norms).

Like other motives, the culture-transmission motive is not constantly present as a conscious desire in the minds of the members of social groups. Rather, it has the form of 
a latent concern of which the group members become aware only under special circumstances, especially if they perceive or suspect a threat to the transmission of their culture. We assume that this occurs regularly when a sociocultural group comes into the sphere of influence of a different, more powerful group. That is, in a foreign cultural majority environment, the culture-transmission motive of the minority is activated. In this activated form, it then motivates actions aimed at countering the perceived threat to cultural transmission, such as "cultural" education in the family or activities in the field of public education (e.g., the founding of own schools).

2.2. Evolutionary Foundations of Cultural Transmission. The second, "evolutionary" component of the theory of cultural transmission in minorities consists of a set of assumptions about the historical origin and function of the basic motives and strategies of minorities and majorities in cultural transmission situations. This component of our model is based on a theory of cultural evolution proposed by Wilson ([33, 37]; see also [38]). According to Wilson's theory, certain ideological systems such as "religion" or "culture" constitute the nonbiological or cultural heritage of social groups that evolved in the course of history because it ensured the survival and reproduction of groups by allowing them to behave as adaptive units. Accordingly, the central approach to the explanation of a social phenomenon by this theory of cultural evolution is the attempt to explain the phenomenon in question as a group-level cultural adaptation.

In our theory of cultural transmission in minorities, we use this evolutionary approach to explain the existence of the postulated culture-transmission motive: we assume that this motive is a product of cultural evolution. The reasoning is as follows: The continued existence of sociocultural groups necessarily requires the transmission of their cultural systems to the next generation. Therefore, other factors constant, groups who manage to transmit their culture better than others to the next generation are at an advantage. As a result, one can expect that all sociocultural groups have evolved mechanisms that support their cultural reproduction. The core of these mechanisms, we propose, is the culture-transmission motive: the appreciation of one's own culture and the implicit or explicit "mission" to transmit it to the next generation [12].

In addition to explaining the existence of the culturetransmission motive, the theory of cultural evolution also allows to explain, in part, the contents of this motive: The theory predicts that the culture-transmission motive should focus on those elements of culture in the broad sense of the term (i.e., the totality of socially transmitted information, [38]) that are particularly important for the preservation of culture. These core cultural elements comprise, on the one hand, the values and norms of the group and the ideology that supports them, such as beliefs about a common origin and a shared destiny, and on the other hand, group characteristics that are reliable outward signs of a person's cultural identity and thereby allow group members-the carriers of the same cultural values and norms-to recognize each other $[11,12]$. These characteristics include, importantly, the group's language or sociolect ([38]; see also [27]). In addition, language is also of fundamental importance for cultural transmission because it is the central channel for the transmission of cultural information $[11,12]$.

The theory of cultural transmission in minorities predicts that the postulated culture-transmission motive, while not immutable, is relatively stable or persistent, even in minorities in a foreign majority cultural environment. One reason for this stability is the existence of strategies to cope with challenges to cultural transmission such as those posed by migration (e.g., [19, 39, 40]). Another reason for the stability of the culture-transmission motive is the structure of this motive: We assume that, during socialization, the culture-transmission motive becomes firmly rooted, through cultural meaning stipulations, in more basic motives. That is, individuals are explicitly and implicitly taught, as part of the socialization process, that adherence to the cultural system of the group offers cognitive guidance, security, and the appreciation and support of the group members (see, e.g., [41]).

Because of the focus of the culture-transmission motive on the described core elements of culture, it is possible for members of a minority to adopt many elements of a majority culture while retaining their identification with the culture of origin. Elements of the majority culture can be particularly easily adopted if they do not conflict with the values and norms of the minority culture. These and further assumptions of the theory of cultural transmission in minorities are described in more detail by Mchitarjan and Reisenzein [1113].

2.3. Aims of the Present Study. The aim of the empirical study reported in this paper was to provide a first direct test of central assumptions of the theory of cultural transmission in minorities, using an online survey of adolescents and young adults with an immigrant background in Germany. Specifically, six hypotheses derived from the theory were tested.

(1) Migrants, like all sociocultural groups, have a culturetransmission motive, that is, a special appreciation of their culture of origin and the desire to transmit it to the next generation.

(2) The culture-transmission motive focuses on the values and norms of the culture of origin, as well as on reliable outward signs of cultural identity, in particular the language.

(3) The culture-transmission motive is based on, or derived from, more basic motives.

(4) The culture-transmission motive is comparatively stable, even in minorities living in a cultural majority environment.

(5) The culture-transmission motive is activated in migration situations and then motivates actions (e.g., pedagogical activities) designed to cope with the problem of the increased difficulty of cultural transmission under conditions of migration. 
(6) Migrants, even those who have at first sight a bicultural identity, identify themselves with one sociocultural group-either their culture of origin, or the majority society. Although not strictly entailed by the present theory, this prediction is suggested by the consideration that (a) according to the theory, a true bicultural identity requires more than acculturation on a superficial behavioral level; it also requires the merging of norms and values (see also, [3]) and (b) such a merger can be difficult to achieve, particularly if the value systems of the two cultures are very different.

\section{Method}

3.1. Participants. The target group of the study was adolescents and young adults with an immigrant background in Germany belonging to minorities who (a) are relatively strongly represented in Germany and (b) differ, according to the results of several studies, in the degree of integration into the educational system, or their educational success (e.g., [40, 42-46]). (Educational success is regarded as a key indicator of the integration of immigrants into mainstream society in recent migration and acculturation research.) Based on these criteria, we included adolescents and young adults with Spanish and Greek immigrant backgrounds (comparatively high educational success), Turkish background (relatively low educational success), and Russian background (average educational success; [46]) in a short list. An additional criterion for the selection of the target groups was the existence of an Internet portal for the immigrant community. At the time of the survey, such "ethnoportals" existed for Russian, Turkish, and Greek immigrants to Germany. However, the forum area of the Greek portal (ellines.de) was not operative at the time of data collection. Therefore, the link to the questionnaire could only be placed on the Russian ethno-portal germany.ru (54.000 registered members) and the Turkish ethno-portal vaybee.de (230.000 registered members).

During the survey period ( 4 months), a total of 55 questionnaires were completed. Forty-eight of the 55 participants had a Russian and seven a Turkish immigrant background; 42 were female and 13 were male, with ages ranging from 16 to 43 years $(M=29.1, S D=5.9)$. Average length of stay in Germany was 11.9 years $(S D=8.5)$. Five of the seven participants of Turkish origin were born in Germany and hence qualified as second-generation immigrants, whereas the participants of Russian origin came to Germany as children or adolescents and hence can be regarded as "1.5 generation" immigrants [8]. They are children of Russian repatriates, former citizens of Russia who were admitted to Germany because of their German ancestry, or on the basis of their Jewish family background. $80 \%$ of the participants had a high school diploma that qualified for study at the university and $45 \%$ attended university or had a university degree. The majority of the participants were employed (23) or studying (16), the rest were looking for a work or training place (11), attended school (1), or "did something else" (4).
3.2. Development of the Questionnaire. To test the previouslydescribed hypotheses, we developed a questionnaire containing a total of 137 items, which was subsequently implemented as a web survey.

3.2.1. Measurement of the Culture-Transmission Motive. The largest group of questionnaire items served to measure the culture-transmission motive postulated by the theory of cultural transmission in minorities: its existence, structure, and content, and its relation to other, more basic motives (Hypotheses 1-3). Our approach to measuring the culturetransmission motive was based on the assumption that motives (desires, preferences) can be assessed both directly and indirectly: Directly, by asking respondents about the strengh or importance of the desires of interest; indirectly, by inferring motives from emotions and actions in which they manifest themselves (e.g., [26, 31, 32]). Accordingly, we constructed three groups of items to measure the culturetransmission motive.

The first item group was intended to provide a direct assessment of the culture-transmission motive-the appreciation of one's culture and the desire to maintain it and transmit it to the next generation. The participants were asked to indicate (a) how dear their culture of origin is to them and (b) how important it is for them to preserve their culture of origin and transmit it to the next generation. Several items were formulated to assess each of these facets of the culture-transmission motive; to save space, they are reported in Section 4 (Tables 1-3).

A second group of items was constructed to measure the culture-transmission motive indirectly, by inferring it from diagnostic emotional reactions. The participants were asked how they would react emotionally to hypothetical events which fulfilled or frustrated the desire for cultural transmission. This method of motive measurement is based on the assumption that the fulfillment of desires elicits positive feelings, whereas their frustration elicits negative feelings (e.g., [47]). Emotional reactions can therefore be used as indirect indicators of motives (see also, [31, 48]). Two different groups of items were used as emotional indicators of the culture-transmission motive. First, we asked the participants to indicate how much they would regret the loss of central cultural elements (language; religion or the nonreligious world view of the family), as well as the complete disappearance of their culture of origin. Second, we asked the participants to report the intensity of negative feelings (anger, shame) elicited by critical reports in the media about their culture, country of origin, or the immigrant community, and the intensity of positive emotions (joy, pride) elicited by positive media reports.

A third group of items also measured the culturetransmission motive indirectly, by assessing actions or action tendencies considered to be diagnostic of the motive. Participants were asked (a) to indicate which group they would support in a concrete conflict of interests (an international sporting competition between their home country and Germany); (b) to which degree they would feel obliged to help a member of their cultural community who had run into trouble; and 
(c) to which degree they, as well as their parents, would prefer a person from their culture of origin as a marriage partner. Marriage partner preference has been used in several prior studies, next to knowledge of the minority language, as a central indicator of the integration versus segregation of minority groups (see e.g., [17]). From the perspective of the theory of cultural transmission in minorities, too, marriage partner preference should be a good behavioral indicator of the strength of the culture-transmission motive, because the maintenance of the culture of origin and its transmission to one's children can be more easily achieved with a partner from the same ethnic group than with a partner from a different culture [13].

\subsubsection{Anchoring of the Culture-Transmission Motive in Basic} Motives and Subjective Reasons for the Preservation of Culture. The theory of cultural transmission in minorities assumes that the culture-transmission motive is acquired via social learning experiences, particularly those designed to anchor the attachment to the culture and its representatives (the cultural group) in more basic motives: The individual is taught, explicitly or implicitly, that the cultural system and the group of people that adhere to it offer cognitive guidance, security, and support (Hypothesis 3). (It can be argued that once the individual accepts this, the wish to maintain and transmit the culture follows naturally. However, the social learning of the culture-transmission motive can also include direct teachings of the importance of maintaining one's culture.) On the assumption that individuals are aware of these social functions of groups, this hypothesis can also be tested by questioning the participants. Accordingly, we asked the participants to indicate the degree to which they ascribed to their culture of origin each of six possible social functions: "my culture of origin reminds me of my roots," "it gives me orientation in my life," "it gives me the feeling of being able to rely on other group members and their support," "it gives me a sense of protection," "it gives me a feeling of security," "it gives me stability," and "it gives me the feeling of being appreciated by others".

Mchitarjan and Reisenzein [11, 12] also proposed several evolutionary functions of holding on to one's culture of origin in a foreign cultural environment. These evolutionary functions are adaptive effects of maintaining the culture of origin that need not be recognized as such, much less consciously pursued, by migrants. However, historical case studies suggest that these adaptive effects are sometimes also pursued as conscious goals (e.g., [19]). If so, these goals provide an additional source of motivation for cultural transmission. To answer the question to what extent this was also the case in our sample, the participants were asked to state their personal reasons for desiring the maintenance and transmission of their culture of origin, by rating the importance of several possible reasons provided to them. Two of these reasons referred to the value of cultural maintenance in the case of a temporary or permanent return to the home country: "I or my children may some day want to return to the home country of my family to live or work there for a while," "... to stay there permanently." Two additional reasons referred to emotional attachments to the cultural group: "It is important for me to maintain my culture of origin and transmit it to my children because I have an emotional attachment to the culture," "... because it would be a pity to lose this culture." These items were included because we reasoned that citing emotional likings and dislikes as reasons would be characteristic for motives that have become functionally autonomous [34]. All of these items were answered on a 0 (do not agree at all) to 7 (agree completely) scale.

\subsubsection{Strategies to Cope with Threats to Cultural Transmission.} Hypothesis 5 claims that the culture-transmission motive is activated in migration situations and then motivates actions aimed at countering the threats to cultural transmission posed by living in a foreign cultural majority environment. To test this hypothesis, two groups of items were constructed. First, the participants were asked what countermeasures they would take in the case of a threat to their cultural transmission caused by (a) the unavailability of important cultural transmission channels in Germany or by (b) detracting influences of the German culture (e.g., organize private language lessons; promote contacts of the child to members of the own cultural group). Second, the participants were asked about their wishes to have the language of origin considered in German public schools. This item was intended to assess the minority's desire for support of their cultural transmission by the majority (cf. $[11,12])$. More details about these items are reported in Section 4.

3.2.4. Cultural Identity. To test Hypothesis 6 concerning migrants' cultural identity, we first asked the participants how they would describe their cultural belonging: "Russian [Turkish]," "more Russian [Turkish] than German," "half/half," "more German than Russian [Turkish]," and "German." Self-categorization measures of this kind have been often used in previous research on ethnic identity (e.g., $[17,39]$ ). Four additional items were formulated to measure cultural adaptation and biculturalism on the behavioral level (see [3]): "I feel at ease among Russian [Turkish] people," "I feel at ease among Germans," "I am able to easily switch between the Russian [Turkish] and the German culture," and "I find it hard to switch between the two cultures." Two more items were constructed to assess acculturation at the deep level (the level of values and norms): "Even if I adjust to the German culture on the outside, my inner values remain the values of the Russian [Turkish] culture" and an analogous item with cultures exchanged. These items, too, were answered on a 0 (do not agree at all) to 7 (agree completely) scale. Finally, we asked the participants how often they were conscious of their non-German cultural origin in their daily lives $(0=I$ never think of it to $7=I$ am conscious of it all the time).

3.2.5. Other Items. A further group of items (not analyzed in this paper) assessed norms and values of the respondents and practices of cultural transmission in the family. Finally, a relatively large battery of questions assessing demographic variables was included. 
3.3. Implementation of the Web Survey. The questionnaire was written in German but was tailored to the two migrant groups by addressing them by name in the items of their respective version of the questionnaire. The links to the questionnaires were published in the forum areas of the Turkish ethno-portal vaybee.de and the Russian ethno-portal germany.ru. The survey was anonymous. As an incentive, potential participants were offered the possibility to take part in a lottery in which two 50-Euro prizes were raffled. Participants were informed that the goal of the survey was to obtain information "about the role of the culture of origin for young people with a migration background in Germany."

\section{Results}

Because of the small number of participants with a Turkish background and because the theory of cultural transmission in minorities is meant to apply to all ethnic minorities, we refrain from a comparative analysis of the two migrant groups. However, the descriptive results obtained for key items (e.g., those measuring the culture-transmission motive) were highly similar for the two groups.

\subsection{Existence and Content of the Culture-Transmission Motive} (Hypotheses 1 and 2). Hypothesis 1 claims that minorities, like all sociocultural groups, have a culture-transmission motive; Hypothesis 2 holds that this motive focuses on norms and language. If these hypotheses about the existence and content of the culture-transmission motive are correct, then the majority of the respondents should (a) endorse both the items used to measure the desire for cultural transmission in general and those focusing on language and norms, and (b) these items should be highly correlated (as high as permitted by measurement error and the fact that three different measurement methods were used).

Tables 1-3 show the items used to measure the culturetransmission motive, together with the frequency distributions of the obtained answers. To facilitate communication (see [49]), we use violin plots $[49,50]$ to visualize the frequency distributions. A violin plot is a combination of the boxplot $[51,52]$ with a representation of the estimated density function of the variable (essentially a smoothed histogram). For better visualization, the density function is mirrored on the $x$-axis. The resulting graph, which resembles a violin, enriches the information provided by the boxplot (about the central tendency and variability of the variable) with information about the shape of the distribution (e.g., skewness, modality).

Table 1 shows the results for the items used for the direct measurement of the culture-transmission motive. The participants were asked to rate (a) how important their culture of origin is for them $(0=$ not at all to $7=$ very important; questions 1-2) and (b) how important the preservation and transmission of their culture of origin is for them (questions 4-6). Note that several items were negatively formulated to counteract possible response tendencies. The response scales of these items were inverted for analysis; therefore, higher values always indicate a stronger culture-transmission motive.

As can be seen, most participants gave high ratings to nearly all items; the medians (indicated by the white circles in the violin graphs) ranged from 5 (norms) to 7 (all other items) on the 0-7 scale. To check the homogeneity of the items, we conducted an exploratory factor analysis. Following recent best practices recommendations ([53]; see also [54]), we used a principal factor analysis (principal axes) with correlated factors (oblique rotation; we used the oblimin method) and determined the number of factors by means of parallel analysis [55]. Note that because of the high intercorrelations of the items, the sample size of $N=55$ is sufficient to obtain replicable factors [56, page 24]. After exclusion of one extremely skewed item ("I reject the culture of my family"), parallel analysis suggested a one-factor solution. On the resulting factor, all items had high loadings. The consistency of the scale formed by computing the mean of these items (CTM-Desire) was Cronbach's $\alpha=0.84$.

Table 2 shows the items used to assess the culturetransmission motive indirectly, by diagnosing it from emotional reactions. As can be seen, most participants said they would be very sorry if their language or their culture of origin were lost. By comparison, regret about the loss of religion or the non-religious world view of the family was much less pronounced (median $=3$ ). However, as can be seen from the violin plot, there were large individual differences on this item. A follow-up analysis revealed that approximately $25 \%$ of our sample identified themselves as non-religious, and it was primarily these respondents who had low scores on this item (median for the remaining sample $=4.5$ ). (We had used the term "non-religious world view" to address the ethical norms of non-religious participants; however, the obtained results suggest that the chosen formulation was unsuited for this purpose. A better approach in future studies might be to ask respondents about the importance of transmitting specific ethical and cultural values.) Table 2 shows, furthermore, that critical as well as positive media reports about the culture of origin or the migrant community do not leave the respondents cold; rather, they are angered by the criticism and happy about the praise. After the exclusion of two items (turning away from religion, feeling shame in response to criticisms of the cultural group), parallel analysis suggested a one-way factor solution. On the resulting factor, all items loaded highly and the scale formed from these items (CTM-Emotion) had high internal consistency $(\alpha=0.85)$.

Table 3 shows the results for the items used to diagnose the culture-transmission motive from motive-diagnostic actions or action tendencies, that is, actions or action tendencies in which this motive was expected to manifest itself particularly clearly. At an international sports competition, most participants would keep their fingers crossed for the team of their culture of origin (42\%), followed by "for both teams equally" (34\%) and "for the German team" (24\%). Furthermore, the majority preferred (i.e., checked a scale value > 3.5 , the scale midpoint) a person from their cultural group as a marriage partner (median $=4$ ); however, a subgroup apparently preferred a German husband or wife. Quite similar, only more extreme are the partner preferences of the respondents' 
TABLE 1: Direct measurement of the culture-transmission motive.

The Russian [Turkish] culture of my family has no importance for me.

$(0=$ absolutely true, 7 = not true at all; reversed item $)$

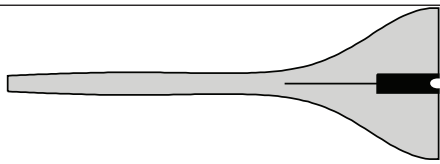

$\begin{array}{llllllll}0 & 1 & 2 & 3 & 4 & 5 & 6 & 7\end{array}$

${ }^{*}$ I reject the Russian [Turkish] culture of my family.

$(0=$ absolutely true, $7=$ not true at all; reversed item $)$

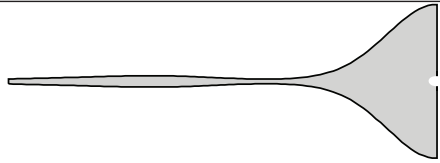

$\begin{array}{llllllll}0 & 1 & 2 & 3 & 4 & 5 & 6 & 7\end{array}$

How important to you are the values and norms of the Russian [Turkish] culture-its ideas about the right way to live, its beliefs about what is proper and what not?

$(0=$ not important at all, $7=$ very important $)$

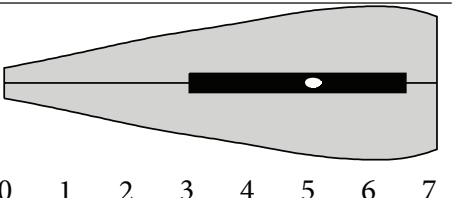

Do you wish that the Russian [Turkish] culture is kept alive in the generation of your (present or future) children?

$(0=I$ do not care at all, $7=I$ wish this very much $)$

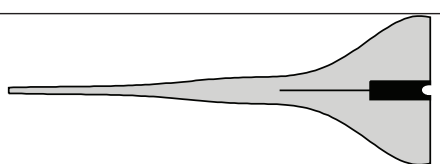

$\begin{array}{llllllll}0 & 1 & 2 & 3 & 4 & 5 & 6 & 7\end{array}$

It would not be important for me to maintain the Russian [Turkish] culture of my family and pass it on to my children.

$(0=$ do not agree at all, $7=$ agree completely; reversed item $)$

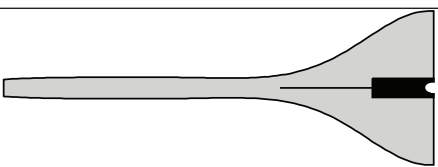

$\begin{array}{llllllll}0 & 1 & 2 & 3 & 4 & 5 & 6 & 7\end{array}$

Would it be important for you to maintain the Russian [Turkish] culture of your family and pass it on to your children?

$(0=$ not important at all, $7=$ very important $)$

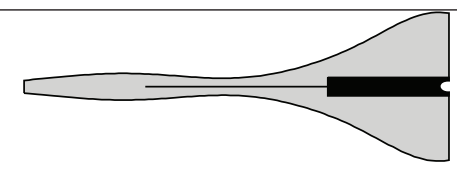

$\begin{array}{llllllll}0 & 1 & 2 & 3 & 4 & 5 & 6 & 7\end{array}$

* Item was excluded from the scale.

Internal consistency of the scale CTM-Desire (Cronbach's $\alpha)=.84$.

parents (as reported by the participants). Furthermore, the participants' own partner preferences and those of their parents were strongly correlated $(r=0.78, P<0.001)$, supporting the hypothesis that this preference is culturally transmitted. Finally, most participants agreed that they should help an acquaintance from their cultural group who was in trouble. The parallel analysis of the items in Table 3 suggested a one-factor solution. The internal consistency of the resulting scale (CTM-Action) was $\alpha=0.74$ and hence is still acceptable.

We expected that the three subscales of the culturetransmission motive (the desire, emotion, and action subscales, Tables 1-3) would correlate relatively strongly (because they all measure the same motive), although not perfectly (because they represent different methods of measuring the culture-transmission motive, each of which contributes method-specific variance, and also because they focus partly on different facets of culture). This prediction was borne out: the scales CTM-Desire, CTM-Emotion, and CTM-Action correlated with each other at 0.69 (desire and emotion), 0.60 (desire and action), and 0.47 (emotion and action), all
Ps $<0.001$. In the following analyses, we use the direct measurement of the culture-transmission motive (i.e., the subscale CTM-Desire). However, completely parallel results were obtained when the scale formed by all items (CTM-Total, $\alpha=0.90$ ) was used as the measure of the culture-transmission motive.

4.2. Anchoring of the Culture-Transmission Motive in Basic Motives and Subjective Reasons for the Preservation of Culture (Hypothesis 3). Table 4 shows the results obtained for (a) items used to assess perceived functions of the culture of origin for the fulfillment of basic motives in which humans' attachment to their cultural system and its representatives (the cultural group) are often thought to be anchored, as well as (b) items that assessed subjective reasons for the importance of cultural transmission.

The responses to most items asking for the importance of the culture of origin and the cultural community in the participants' lives (upper part of Table 4) were centered around the midpoint of the scale, with a relatively wide spread. Hence, all listed social functions of culture 
TABLE 2: Indirect measurement of the culture-transmission motive: Emotional reactions to desire fulfillment and frustration.

Would you feel sorry if your (present or future) children would forget or lose the Russian [Turkish] language?

$(0=I$ would not mind, $7=I$ would feel very sorry $)$

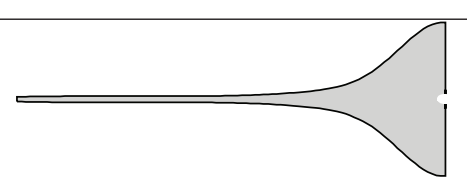

Would you feel sorry if your (present or future) children would turn their back on the religion of your family/the non-religious world view of your family? $(0=I$ would not mind, $7=I$ would feel very sorry)

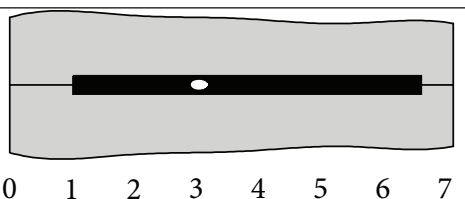

A hypothetical question: Would you feel sorry if — for whatever reason—-the Russian [Turkish] culture would not exist anymore 500 years from now?

$(0=I$ would not mind, $7=I$ would feel very sorry $)$

How do you feel if something negative is reported on German television, radio or the newspapers about Russia [Turkey], the Russian [Turkish] culture, or the Russian [Turkish] community?

I do not mind. I do not feel addressed by these news $(0=$ absolutely true, $7=$ not true at all; reversed item)
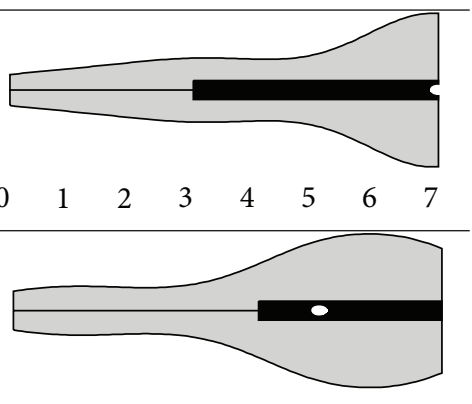

${ }^{*}$ I feel ashamed, particularly if the criticism is justified.

$(0=$ not true at all, $7=$ absolutely true $)$

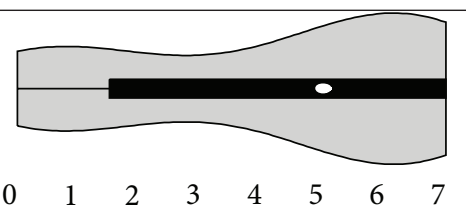

How do you feel if something positive is reported on German television, radio, or the newspapers about Russia [Turkey], the Russian [Turkish] culture, or the Russian [Turkish] community?

I do not mind. I do not feel addressed by these news. ( $7=$ not true at all, $0=$ absolutely true; reversed item $)$

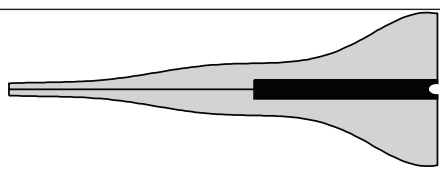

$\begin{array}{llllllll}0 & 1 & 2 & 3 & 4 & 5 & 6 & 7\end{array}$

This makes me happy.

$(0=$ not true at all, $7=$ absolutely true $)$

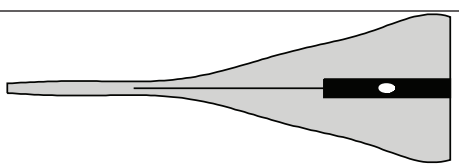

$\begin{array}{llllllll}0 & 1 & 2 & 3 & 4 & 5 & 6 & 7\end{array}$

I feel proud.

$(0=$ not true at all, $7=$ absolutely true $)$

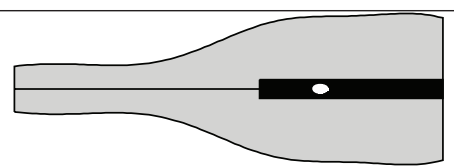

$\begin{array}{llllllll}0 & 1 & 2 & 3 & 4 & 5 & 6 & 7\end{array}$

\footnotetext{
* Item was excluded from the scale.

Internal consistency of the scale CTM-Emotion (Cronbach's $\alpha)=.85$.
} 
TABLE 3: Indirect measurement of the culture-transmission motive: Motive-diagnostic actions.

Imagine an international sports competition where the national team of Russia [Turkey] and the German team play against each other. For which team would you more likely keep your fingers crossed? ( 1 = for the German national team, 2 = for both teams equally, 3 = for the Russian [Turkish] national team)

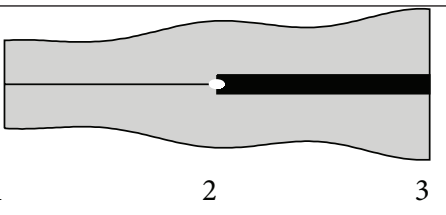

As my husband/wife, I prefer a man/woman from the Russian [Turkish] culture $(0=$ do not agree at all, 7 = agree completely)

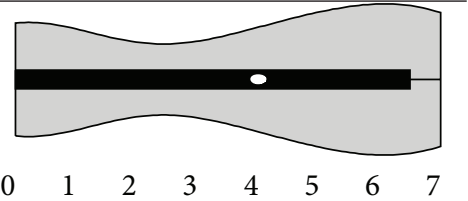

As my husband/wife, my parents prefer a man/woman from the Russian [Turkish] culture $(0=$ do not agree at all, 7 = agree completely)

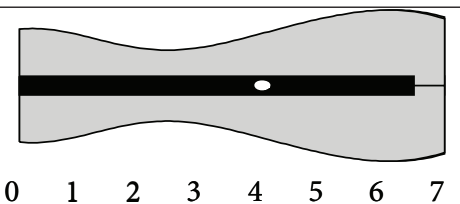

If an acquaintance of Russian [Turkish] origin is in trouble, I should help him or her $(0=$ do not agree at all, $7=$ agree completely)

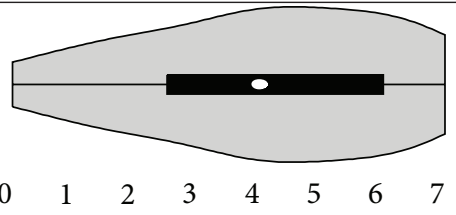

Internal consistency of the scale CTM-Action (Cronbach's $\alpha)=.74$

and cultural groups were to some degree ascribed to the culture of origin. The different social functions were fairly strongly intercorrelated, indicating that the culture of origin tended to play all functions simultaneously. Furthermore, all items correlated significantly with the culture-transmission motive $(P<0.01$ or better $)$, with the highest correlation (0.68) obtained for the item "My culture reminds me of my roots," which also had the highest mean rating (Table 4); the remaining correlations were of medium size (around 0.55). To test Hypothesis 3 that the desire to transmit the culture is derived from basic motives fulfilled by the culture of origin, CTM-Desire was predicted from the social function items using multiple regression. Supporting the hypothesis, a high multiple correlation of $R=0.81(P<0.001)$ was obtained.

The lower part of Table 4 shows the results obtained for the items assessing subjective reasons for the importance of cultural transmission. The items concerning return intentions were on average endorsed with medium strength, with a wide spread. By contrast, the two "emotional" reasons for holding on to the culture of origin received high approvals: "... because I have an emotional attachment to the Russian [Turkish] culture" and "... because it would be a pity to lose this culture." The culture-transmission motive was again significantly $(P<0.01$ or better) related to all items; correlations to return intentions were moderate ( 0.39 permanent; 0.48 temporary), but strong correlations were found for the emotional attachment items $(0.75 ; 0.79)$. CTM-Desire could be very well predicted from the subjective reasons for cultural preservation, $R=0.83(P<0.001)$.

4.3. Stability of the Culture-Transmission Motive (Hypothesis 4). The theory of cultural transmission in minorities predicts that the culture-transmission motive is relatively stable or persistent, both within the individual carriers of culture across their lifespan (because it is firmly "implanted" during socialization) and to a lesser degree also across generations (because it is itself transmitted as part of the culture and thus should be at least as stable as are core transmitted values). To test the intragenerational stability of the culture-transmission motive in our sample, we correlated the strength of the motive of the individual participants with their length of stay in Germany (the variance of length of stay in our sample seemed sufficient to make this test meaningful: $S D=8.5$, $M=11.9$ ). If the culture-transmission motive is persistent, its correlation with length of stay should be low. In accord with this prediction, the Pearson correlation between the culturetransmission motive and length of stay in Germany was $r=$ -0.03 (ns).

To test the intergenerational stability of the culturetransmission motive, we correlated the participants' score on the CTM-Desire scale with the strength of the culturetransmission motive of their parents, as reported by the participants (measured with the item: "How important is it/was it for your parent[s] of Russian/Turkish origin to keep their culture of origin in Germany?"). The obtained correlation of $r=0.47, P<0.001$ suggests moderate intergenerational stability of the culture-transmission motive.

\subsection{Strategies to Cope with Threats to Cultural Transmission} (Hypothesis 5). Table 5 shows the results obtained for the items asking about coping strategies in the case of a threat to cultural transmission. The participants were presented with two main challenges to cultural transmission posed by living in a foreign cultural majority environment, plus a list 
TABLE 4: Perceived social functions of the culture of origin and subjective reasons for the preservation of culture.

What is the role played by the Russian [Turkish] culture in your life? In what ways is this cultural community important for you?

It reminds me of my roots.

$(0=$ not true at all, $7=$ absolutely true $)$

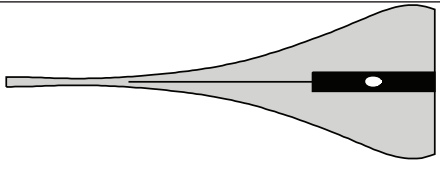

$\begin{array}{llllllll}0 & 1 & 2 & 3 & 4 & 5 & 6 & 7\end{array}$

It gives me orientation in my life.

$(0=$ not true at all, $7=$ absolutely true $)$
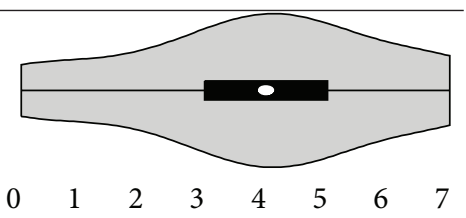

It gives me the feeling of being able to rely on other group members and their support. $(0=$ not true at all, $7=$ absolutely true $)$
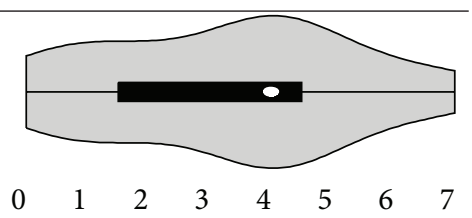

It gives me a sense of protection.

$(0=$ not true at all, $7=$ absolutely true $)$

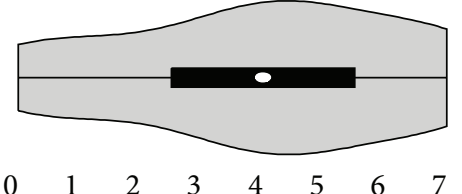

It gives me a feeling of security.

$(0=$ not true at all, $7=$ absolutely true $)$
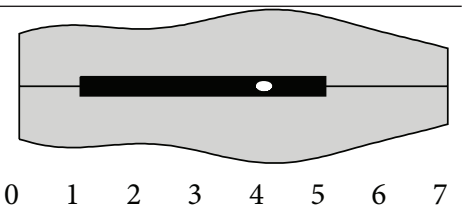

It gives me stability.

$(0=$ not true at all, $7=$ absolutely true $)$
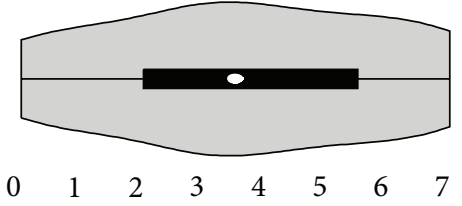

It gives me the feeling of being appreciated by others.

$(0=$ not true at all, $7=$ absolutely true $)$

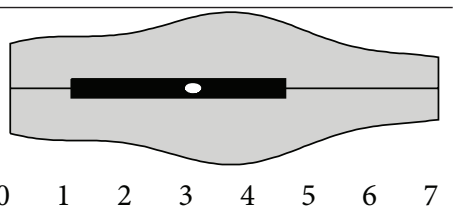

Why would it be important for you to keep the Russian [Turkish] culture of your family and pass it on to your (presents or future) children? (Skip this question if keeping and transmitting your culture of origin is not at all important to you).

Because I or my children may some day want to return to the home country of my family, to live or work there for a while.

$(0=$ not at all true, $7=$ definitely true $)$
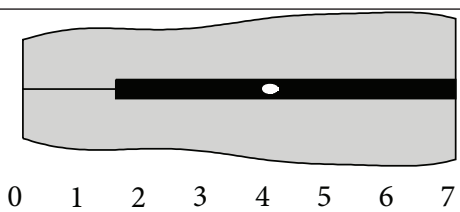

Because I or my children may some day want to return permanently to the home country of my family.

$(0=$ not at all true, $7=$ definitely true $)$

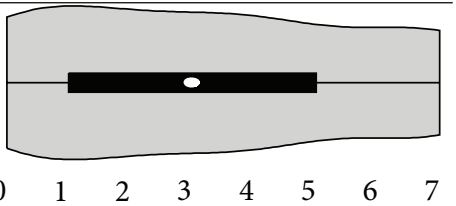


TABle 4: Continued.

Because I have an emotional attachment to the Russian [Turkish] culture.

$(0=$ not at all true, $7=$ definitely true $)$

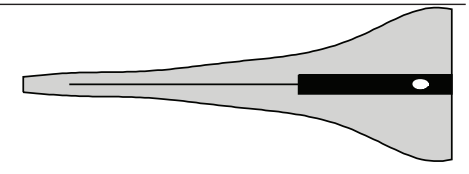

$\begin{array}{llllllll}0 & 1 & 2 & 3 & 4 & 5 & 6 & 7\end{array}$

Because it would be a pity to lose this culture.

$(0=$ not at all true, $7=$ definitely true $)$

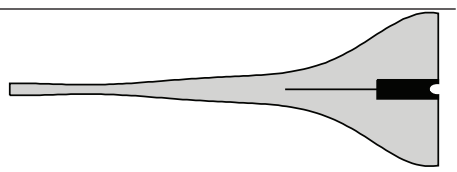

$\begin{array}{llllllll}0 & 1 & 2 & 3 & 4 & 5 & 6 & 7\end{array}$

TABLE 5: Strategies to cope with threats to cultural transmission.

What would you do if there is no possibility for your (present or future) child to learn the Russian [Turkish] language in a German public school?
What would your reaction be if your (present or future) child would drift away from the Russian [Turkish] culture (e.g., does not abide by the culture's views about the "proper" way to live; loses the language).
Do something else

Try to found a private school together with others

Organize language lessons together with other parents

Send child to a private language course

Teach language at home

Would not do anything

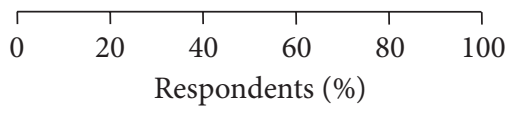

Restrict contact of the child

to Germans

Send child for a while to the country of origin of my family

Promote contacts of my child to people from the culture of origin

Would not do anything

Would be alarmed

Would be disappointed

Would be sad

Would not mind

\begin{tabular}{llllll}
\hline & 1 & 1 & 1 & \\
0 & 20 & 40 & 60 & 80 & 100
\end{tabular}

Respondents (\%) of possible reactions to them, and were asked to check all answers that applied to them.

The results can be summarized as follows. First, almost all respondents said they would take some form of action if their child could not learn the mother tongue in a public school in Germany: 95\% said they would teach the language at home, $36 \%$ would (also) "send the child to a private language course, if that is possible," and $23 \%$ would "organize language lessons together with other parents." Second, virtually none of the respondents remains emotionally unmoved if their child is drifting away from the culture of origin; rather, they feel sad, disappointed, and even alarmed. In addition, all 55 participants stated that they would take at least one countermeasure against the threat of cultural loss, from "promoting contact of the child to people from the culture of origin" (37\%) to "restricting contact of the child to Germans" (7\%).
Third, the tendency to act, that is, to do something about the impending loss of culture, could be partly predicted from the culture-transmission motive: the stronger the culturetransmission motive, the more countermeasures were taken against the possible loss of language $(r=0.34, P<0.01)$ and the drifting away of the child from the culture of origin $(r=0.37, P<0.01)$.

The participants were also asked to what extent they would like to see their language of origin considered in public education in Germany. The vast majority (91\%) preferred for their children school instruction in German, with the language of origin as an optional (49\%) or a compulsory (42\%) subject. The remaining participants (7\%) preferred teaching in the language of origin, with or without German as an additional subject. Furthermore, the stronger the culture-transmission motive of the respondents, the more 
they wanted the language of origin to be considered in public education, $r=0.48, P<0.001$. The preference for German as the teaching language can be explained by the belief of most respondents that good German language skills are essential for social success in Germany: 90\% of the respondents maximally agreed with (scale value 7) the statement "If I want to get to the top in Germany, I must most of all know good German."

4.5. Cultural Identity. Replicating similar findings of previous studies (e.g., [17]), we found that all participants identified themselves at least partly, and a majority (58\%) even primarily, with their culture of origin: $29 \%$ described themselves as "Russian [Turkish]," 29\% as "more Russian [Turkish] than German," and another $27 \%$ as being "half Russian [Turkish]/half German;" 15\% described themselves as "more German than Russian" [Turkish];" nobody called him- or herself "German". In addition, as predicted by the theory of cultural transmission in minorities, the degree of self-identification with the culture of origin correlated significantly with the culture-transmission motive $(r=0.52$, $P<0.001)$. Also in accord with the theory, the respondents said they were very often conscious of their non-German cultural origin in their daily lifes (median $=5$ on the 0 7 scale), and this was more strongly the case, the stronger their culture-transmission motive, $r=0.45, P<0.001$. This could mean that the culture-transmission motive, which according to the theory of cultural transmission in minorities is chronically activated in immigrant minorities, sensitizes them to their ethnic identity.

Although $58 \%$ of the participants identified primarily with their culture of origin, $71 \%$ self-described themselves as bicultural, that is, as being both Russian [Turkish] and German. This replicates previous findings that secondgeneration migrants are typically bicultural in terms of their self-ascribed identity (see [57]). Most of our respondents are also qualified as behavioral biculturals, defined as people who show "comfort and proficiency with both one's heritage culture and the culture of the country or region in which one has settled" [58, page 26]: the majority of our respondents said that they felt equally at ease among people from their culture of origin $(M=5.3)$ and among Germans $(M=5.0)$ and that they were able to easily switch between the two cultures $(M=5.7$; see also [57]).

However, these findings do not necessarily mean that our participants are bicultural at a deep level, that is, have merged values and norms. Indeed, we found that most participants agreed to the statement "Even if I adjust to the German culture on the outside, my inner values remain the values of the Russian [Turkish] culture" (median $=5$ ) but not to the reverse statement (median $=2$ ). A more detailed analysis of the answers given by the 39 participants who had described themselves as bicultural ("Russian [Turkish]-German," "half/ half," or "German-Russian[Turkish]") revealed the following: Fourteen of them clearly agreed (scale values $5-7$ ) that they were Russian [Turkish] "on the inside" and disagreed that they were German "on the inside"; whereas three claimed they were German but not Russian [Turkish]; together, these make for 17 (44\%) bicultural participants who considered themselves monocultural "on the inside." The remaining $56 \%$ either agreed with both statements (5) or from partly to completely rejected both (17) (scale values $0-4$ ). The possible reasons behind these answers will be examined in Section 5 .

\section{Discussion}

The results of the study provide support for the majority of the tested hypotheses.

Hypothesis 1. Migrants, like all sociocultural groups, have a culture-transmission motive.

The most direct evidence for this hypothesis is the high endorsement of the items asking for (a) the importance of the culture of origin and (b) the desire for cultural transmission. The relevant items formed a one-factorial scale (CTM-Desire) with high internal consistency. Furthermore, this direct measurement of the culture-transmission motive correlated sufficiently highly with two indirect motive indicatorsemotional responses to the fulfillment and frustration of the desire for cultural transmission, and motive-diagnostic actions-to support the existence of a common underlying factor (i.e., the culture-transmission motive). For the two indirect indicators of the culture-transmission motive, too, one-factorial scales with adequate internal consistency could be constructed (CTM-Emotion and CTM-Action). The combined scale (CTM-Total) had excellent internal consistency (0.90). Hence, as a side-benefit of the present study, a suitable instrument for measuring the culture-transmission motive is available for future research.

Hypothesis 2. The culture-transmission motive focuses on the values and norms of the culture of origin, as well as on reliable outward signs of cultural identity, in particular the language.

This hypothesis is supported by the high correlations of the items asking for the appreciation of and the desire to transmit values and norms and the language of origin (which were part of the CTM-Emotion subscale) (a) with each other and (b) with the items that asked for the desire for cultural transmission and the appreciation of the culture of origin in general (subscale CTM-Desire, $r=0.69$ ). Additional, indirect evidence for Hypothesis 2 is provided by the significant correlations of the culture-transmission motive of the participants with (a) their readiness to take countermeasures against the threats of language loss and cultural alienation of their children and (b) their wish that the language of origin be considered in German public schools.

Hypothesis 3. The culture-transmission motive is based on, or derived from, more basic motives.

In accord with this hypothesis, the participants gave moderate to high ratings to all of a set of items that assessed perceived social functions of the culture of origin, and the desire to transmit the culture could be very well predicted 
from these items. As to the subjective reasons given by the participants for their wish to transmit the culture of origin, their emotional attachment to the culture was highly salient, although the utility of maintaining the culture in the case of a return to the homeland also played a role.

Hypothesis 4 . The culture-transmission motive is relatively stable, even in minorities living in a cultural majority environment.

The findings support, on the one hand, the predicted intragenerational stability of the culture-transmission motive in people with an immigrant background: There was no significant correlation between the strength of the participants' culture-transmission motive and the length of their stay in Germany. Furthermore, the results suggest moderate intergenerational stability of the culture-transmission motive ( $r=0.47$ between the culture-transmission motive of the participants and the transmission motive of their parents).

Hypothesis 5. The culture-transmission motive is activated in migration situations and then motivates actions (e.g., pedagogical activities) designed to cope with the problem of the increased difficulty of cultural transmission under conditions of migration.

In agreement with this hypothesis, almost all respondents stated that they would take action if their child could not learn the language of origin in a public school, or if they noticed that their child was drifting away from their culture of origin. Also in line with Hypothesis 5 are the results obtained for the desire to have the language of origin considered in public education. Virtually, all respondents wish that their native language is taught either as an optional or even as a compulsory subject. Furthermore, the more important the transmission of culture is to the respondents, the higher is their willingness to take action against a threats to cultural transmission and the stronger is their wish to see the language of origin considered in school.

Hypothesis 6. Migrants, even those who at first sight have a bicultural identity, identify themselves primarily with one sociocultural group.

Although $70 \%$ of the participants self-described themselves as bicultural, we found that about half of them considered themselves to be monocultural "on the inside," that is, in terms of their cultural values. While this finding is in line with Hypothesis 6, the findings for the other half of the biculturals are not. Most of them regarded neither the values of their culture of origin, nor those of the German culture as their core values. This finding could mean (a) that these participants have indeed synthesized elements of both cultural systems into a novel, "mixed," bicultural identity (e.g., $[59,60])$. However, it could also mean (b) that these participants have internalized two cultural identities and switch between them depending on situation or (c) that they are uncertain about their cultural identity, or are in a transitional phase between cultures (see [16]). Further research is needed to decide between these possibilities.
Although the findings of the present study mostly supported the hypotheses derived from the theory of cultural transmission in minorities, we regard them as preliminary. First, the design of the study was not optimal for testing some of the hypotheses (in particular the hypothesis about the intergenerational stability of the culture-transmission motive). Second, the present study is limited by the relatively small and restricted sample-mainly well-educated female adolescents and young adults with a Russian immigrant background. However, note that these participants could actually be regarded as a "unfavorable" sample for testing the theory of cultural transmission in minorities, because one might expect them to show a comparatively high willingness to assimilate into the German culture, for two reasons: First, because of their original German ancestry and because their families' emigration to Germany is meant to be permanent; and second, because of their high education level (assuming that a higher educational level correlates with greater openness with other cultures, a relativization of the importance of one's culture of origin, and cosmopolitan thinking). The act that most predictions were confirmed even in this "unfavorable" sample suggests that the theory of cultural transmission will also be supported in other samples of immigrants. (A more extensive online survey of people with an immigrant background from many different countries is currently under way.)

A possible objection to our results concerns the possibility of self-selection: It could be argued that the respondents were mostly immigrants with a particularly strong culturetransmission motive and that this could have skewed the results in favor of the theory. However, the fact that the results obtained for our sample on variables such as selfidentification with the culture of origin and marriage partner preference were similar to those obtained in previous studies with representative samples of German second-generation (including Russian) immigrants (e.g., [17]) speaks against a serious self-selection problem. Moreover, a self-selection of participants, if present, primarily affects hypotheses about the levels of a variable (e.g., the absolute strength of the culturetransmission motive), not about the relationships between variables, to which the majority of our hypotheses refer (e.g., the correlation between the culture-transmission motive and the willingness to organize private language teaching). For the testing of correlational hypotheses, a representative survey is not needed (see $[61,62])$. Hence, even if the mean level of the culture-transmission motive in our sample overestimates that in the population of " 1.5 generation" Russian immigrants to Germany, or that of immigrants in general, this is no reason to believe that the intercorrelations among the items measuring the culture-transmission motive and the relations of this motive to other variables would be different in representative samples. A nonrepresentative sample is problematic for the testing of correlational hypotheses only if one has reason to assume that the correlation between variables in the sample is substantially different from that in the population-e.g., if the desire for education in the mother tongue decreases rather than increases (as found in our sample) with an increasing culture-transmission motive in the population. However, from an (action-)theoretical perspective, this reverse association is quite implausible. To check this issue empirically, 
we recalculated the correlations relevant to Hypotheses 2-6 while excluding participants with values $\geq 6$ on the culturetransmission motive. This eliminated about $1 / 3$ of the sample. Nevertheless, nearly all correlations remained stable. As to Hypotheses 1 and 2, which (also) speak to the level of the culture-transmission motive, the present theory would also be supported if the culture-transmission motive in secondgeneration migrants is on average only of medium strength, rather than being very high, as in our sample.

As mentioned in Section 1, the theory of cultural transmission in minorities can explain several migration-related phenomena that pose difficulties to existing theoretical accounts. These include the following findings [13]: (1) despite the difficult conditions of migration, immigrant parents are as successful in transmitting cultural norms and values to their children as are parents of nonmigrant families; (2) migrants and their descendants very often have a strong identification with the culture of origin of their families; and (3) the identification of migrants with their culture of origin is not necessarily a barrier to their social integration into the receiving society, at least into its labor market and educational system. The explanatory difficulties that these findings pose to existing migration-theoretic accountsespecially to assimilation theory-have been emphasized by the authors of the respective studies themselves (e.g., [63, page 41f.]; [64, page 226], [65, page 199]; [66, page 222]; see also, [14]). In contrast, from the perspective of the theory of cultural transmission in minorities, these findings are not "anomalies" [67] but expected (because predicted by the theory) social phenomena (cf. $[11,13])$. The first two of these findings are again supported by the results of the present study, either directly (finding 2) or indirectly (finding 1). Finding 3 is also confirmed by our results: The majority of our respondents are successfully integrated into the German education or labor market, despite retaining a strong desire to maintain and transmit their culture of origin. Consistent with this conclusion, the participants of our study considered good knowledge of German, but not cultural assimilation, to be a necessary condition for success in the majority society. The statement "If I want to get to the top in Germany, I must give up my culture" ( $0=$ do not agree at all, $7=$ agree completely $)$ was strongly rejected by almost all participants $(M=1.04$, $S D=1.8$, median $=7$ ).

\section{Conflict of Interests}

The authors declare that there is no conflict of interests regarding the publication of this paper.

\section{References}

[1] S. May, Language and Minority Rights, Routledge, New York, NY, USA, 2005.

[2] U. Schönpflug, Ed., Cultural Transmission. Psychological, Developmental, Social, and Methodological Aspects, Cambridge University Press, Cambridge, UK, 2009.

[3] S. J. Schwartz, J. B. Unger, B. L. Zamboanga, and J. Szapocznik, "Rethinking the concept of acculturation," American Psychologist, vol. 65, no. 4, pp. 237-251, 2010.
[4] A. Zick, Psychologie der Akkulturation: Neufassung eines Forschungsbereiches [The Psychology of Acculturation: Reconceptualization of a Research Area], VS Verlag für Sozialwissenschaften, Wiesbaden, Germany, 2010.

[5] R. D. Alba, Ethnic Identity. The Transformation of White America, Yale University Press, New Haven, Conn, USA, 1990.

[6] H. Esser, Aspekte der Wanderungssoziologie [Aspects of the Sociology of Migration], Luchterhand, Darmstadt, Germany, 1980.

[7] R. E. Park, "The nature of race relations," in Race and Culture, R. E. Park, Ed., pp. 81-116, Free Press, Glencoe, Ill, USA, 1950.

[8] A. Portes and R. Rumbaut, Legacies: The Story of the Immigrant Second Generation, University of California Press, Berkeley, Calif, USA, 2001.

[9] N. G. Schiller, L. Basch, and C. Blanc-Szanton, "Transnationalism: a new analytic framework for understanding migration," in Towards a Transnational Perspective on Migration, N. G. Schiller, N. Basch, and C. Blanc-Szanton, Eds., pp. 1-24, New York Academy of Sciences, New York, NY, USA, 1992.

[10] P. Bourdieu, "Ökonomisches Kapital-Kulturelles KapitalSoziales Kapital [Economic capital-cultural capital-social capital]," in Die verborgenen Mechanismen der Macht. Schriften zu Politik und Kultur [The hidden mechanisms of power. Writings on politics and culture], edited by M. Steinbrücke, pp. 49-80, VSA, Hamburg, Germany, 2005.

[11] I. Mchitarjan and R. Reisenzein, "Kulturtransmission bei Minderheiten: Ein Theorieentwurf [Cultural transmission in minorities]," Zeitschrift für Soziologie der Erziehung und Sozialisation, vol. 30, pp. 421-435, 2010.

[12] I. Mchitarjan and R. Reisenzein, "Towards a theory of cultural transmission in minorities," Ethnicities. In press.

[13] I. Mchitarjan and R. Reisenzein, "The importance of the culture of origin in immigrant families: empirical findings and their explanation by the theory of cultural transmission in minorities," in Migration, Familie und Gesellschaft [Migration, Family, and Society], T. Geisen, T. Studer, and E. Yildiz, Eds., VS Verlag für Sozialwissenschaften, Wiesbaden, Germany, 2013.

[14] A. Bisin and T. Verdier, "The economics of cultural transmission and socialization," in Handbook of Social Economics, J. Benhabib, A. Bisin, and M. O. Jackson, Eds., vol. 1A, pp. 339-416, North-Holland, Amsterdam, The Netherlands, 2011.

[15] A. J. Umaña-Taylor, "Ethnic identity," in Handbook of Identity Theory and Research, S. J. Schwartz, K. Luyckx, and V. L. Vignoles, Eds., pp. 791-809, Springer, New York, NY, USA, 2011.

[16] J. W. Berry, J. S. Phinney, D. L. Sam, and P. Vedder, "Immigrant youth: acculturation, identity, and adaptation," Applied Psychology, vol. 55, no. 3, pp. 303-332, 2006.

[17] U. Boos-Nünning and Y. Karakaşoğlu, Viele Welten leben. Zur Lebenssituation von Mädchen und jungen Frauen mit Migrationshintergrund [Living in Many Worlds. On the Life Situation of Girls and Young Women with Immigrant Background], Waxmann, Münster, Germany, 2nd edition, 2006.

[18] H. Feidel-Mertz and A. Hammel, "Integration and formation of identity: Exile schools in Great Britain," Shofar, vol. 23, no. 1, pp. 71-84, 2004.

[19] I. Mchitarjan, "Das "russische Schulwesen" im europäischen Exil. Zum bildungspolitischen Umgang mit den pädagogischen Initiativen der russischen Emigranten in Deutschland, der Tschechoslowakei und Polen (1918-1939) [The "Russian school system" in the European exile and the educational policies for the Russian emigrants in Germany, Czechoslovakia and Poland (1918-1939]," Zeitschrift für Pädagogik, vol. 52, pp. 732-751. 
[20] C. Sabatier, "Ethnic and national identity among secondgeneration immigrant adolescents in France: the role of social context and family," Journal of Adolescence, vol. 31, no. 2, pp. 185205, 2008.

[21] A. J. Umaña-Taylor and M. A. Fine, "Examining ethnic identity development among Mexican-origin adolescents living in the United States," Hispanic Journal of Behavioral Sciences, vol. 26, no. 1, pp. 36-59, 2004.

[22] R. Polm, "Minderheit [Minority]," in Ethnische Minderheiten in der Bundesrepublik Deutschland. Ein Lexikon [Ethnic Minorities in the Federal Republic of Germany: A Dictionary], C. SchmalzJacobsen and G. Hansen, Eds., pp. 340-342, Beck, München, Germany, 1995.

[23] R. Conte and C. Castelfranchi, Cognitive and Social Action, UCL Press, London, UK, 1995.

[24] H. Esser, Sociology: General Foundations, Campus, New York, NY, USA, 3rd edition, 1999.

[25] R. H. Fazio, "Multiple processes by which attitudes guide behavior: the MODE model as an integrative framework," in Experimental Social Psychology, M. P. Zanna, Ed., vol. 23, pp. 75-109, Academic Press, San Diego, Calif, USA, 1990.

[26] R. Reisenzein, "Motivation [Motivation]," in Handbook of Psychology, K. Pawlik, Ed., pp. 239-247, Springer, Heidelberg, Germany, 2006.

[27] P. Bourdieu, Distinction: A Social Critique of the Judgement of Taste, Routledge, New York, NY, USA, 2006.

[28] H. Esser, "Strukturelle Assimilation und ethnische Schichtung [Structural assimilation and ethnic stratification]," in Interdisziplinäre Jugendforschung, A. Ittel and H. Merkens, Eds., pp. 89104, VS Verlag für Sozialwissenschaften, Wiesbaden, Germany, 2006.

[29] S. Lindenberg, "An assessment of the new political economy: its potential for the social sciences and for sociology in particular," Sociological Theory, vol. 3, pp. 99-114, 1985.

[30] A. Smith, An Inquiry into the Nature and Causes of the Wealth of Nations, W. Strahan \& T. Cadell, London, UK.

[31] S. Reiss, “The sixteen strivings for god," Zygon, vol. 39, no. 2, pp. 303-320, 2004.

[32] S. Reiss and S. M. Havercamp, "Toward a comprehensive assessment of fundamental motivation: Factor structure of the Reiss profiles," Psychological Assessment, vol. 10, no. 2, pp. 97106, 1998.

[33] E. Sober and D. S. Wilson, Unto Others. The Evolution and Psychology of Unselfish Behavior, Harvard University Press, Cambridge, UK, 1998.

[34] G. W. Allport, "The functional autonomy of motives," American Journal of Psychology, vol. 50, pp. 141-156, 1937.

[35] M. Bayar, "Reconsidering primordialism: An alternative approach to the study of ethnicity," Ethnic and Racial Studies, vol. 32, no. 9, pp. 1639-1657, 2009.

[36] T. Modood, Multiculturalism, Polity Press, Cambridge, UK, 2007.

[37] D. S. Wilson, Darwin's Cathedral: Evolution, Religion, and the Nature of Society, University of Chicago Press, Chicago, Ill, USA, 2002.

[38] P. J. Richerson and R. Boyd, Not by Genes Alone. How Culture Transformed Human Evolution, University of Chicago Press, Chicago, Ill, USA, 2005.

[39] W. W. Isajiw and T. Makabe, "Identity maintenance and ethnic family, school and neighborhood: the Canadian context of different migrant groups," in Families in Different Cultures, B. Nauck and U. Schönpflug, Eds., pp. 285-302, Enke, Stuttgart, Germany, 1997.

[40] D. Thränhardt, "Spanische Einwanderer schaffen Bildungskapital: Selbsthilfe-Netzwerke und Integrationserfolg in Europa [Spanish immigrants create educational capital]," in How Migrants Establish Networks and Create Social Capital, D. Thränhardt and K. Weiss, Eds., pp. 93-111, Lambertus, Freiburg im Breisgau, Germany, 2005.

[41] M. Verkuyten, The Social Psychology of Ethnic Identity, Psychology Press, Hove, UK, 2005.

[42] R. D. Alba, J. Handl, and W. Müller, "Ethnische Ungleichheit im deutschen Bildungssystem [Ethnic inequality in the German education system]," Kölner Zeitschrift für Soziologie und Sozialpsychologie, vol. 46, pp. 209-237, 1994.

[43] H. Diefenbach, Kinder und Jugendliche aus Migrantenfamilien im deutschen Bildungssystem [Children and Adolescents from Immigrant Families in the German Education System], VS Verlag für Sozialwissenschaften, Wiesbaden, Germany, 3rd edition, 2010.

[44] C. Kristen, "Hauptschule, Realschule oder Gymnasium? Ethnische Unterschiede am ersten Bildungsübergang. [Ethnic differences at the first educational transition]," Kölner Zeitschrift für Soziologie und Sozialpsychologie, vol. 54, pp. 534-552, 2002.

[45] A. G. Müller and P. Stanat, "Schulischer Erfolg von Schülerinnen und Schülern mit Migrationshintergrund: Analysen zur Situation von Zuwanderern aus der ehemaligen Sowjetunion und aus der Türkei [Educational success of pupils with an immigrant background: analyses of the situation of immigrants from the former Soviet Union and Turkey]," in EthnicityRelated Disparities in the Education System, J. Baumert, P. Stanat, and R. Watermann, Eds., pp. 221-255, VS Verlag für Sozialwissenschaften, Wiesbaden, Germany, 2006.

[46] I. Mchitarjan, "Einwanderer mit deutschem Pass. Aussiedlerkinder in der deutschen Schule [Immigrants with a German passport. Children of Russian repatriates in the German school system]," Schüler. Wissen für Lehrer, Themenheft Migration, pp. 102-105, 2009.

[47] R. Reisenzein and H. Weber, "Personality and emotion," in Cambridge Handbook of Personality Psychology, P. J. Corr and G. Matthews, Eds., pp. 54-71, Oxford University Press, Oxford, UK, 2009.

[48] K. M. Sheldon, A. J. Elliot, Y. Kim, and T. Kasser, "What is satisfying about satisfying events? Testing 10 candidate psychological needs," Journal of Personality and Social Psychology, vol. 80, no. 2, pp. 325-339, 2001.

[49] J. P. Kastellec and E. L. Leoni, "Using graphs instead of tables in political science," Perspectives on Politics, vol. 5, no. 4, pp. 755771, 2007.

[50] J. L. Hintze and R. D. Nelson, "Violin plots: A box plot-density trace synergism," American Statistician, vol. 52, no. 2, pp. 181184, 1998.

[51] J. W. Tukey, Exploratory Data Analysis, Addison-Wesley, Reading, Mass, USA, 1977.

[52] T. J. W. McGill and W. Larsen, "Variations of box plots," American Statistician, vol. 32, pp. 12-16, 1978.

[53] A. B. Costello and J. Osborne, "Best practices in exploratory factor analysis: Four recommendations for getting the most from your analysis," Practical Assessment Research \& Evaluation, vol. 10, no. 7, pp. 1-9, 2005. 
[54] T. R. Hinkin, "A brief tutorial on the development of measures for use in survey questionnaires," Organizational Research Methods, vol. 1, no. 1, pp. 104-121, 1998.

[55] J. L. Horn, "A rationale and test for the number of factors in factor analysis," Psychometrika, vol. 30, no. 2, pp. 179-185, 1965.

[56] B. Thompson, Exploratory and Confirmatory Factor Analysis: Understanding Concepts and Applications, American Psychological Association, Washington, DC, USA, 2004.

[57] A. M. D. Nguyen and V. Benet-Martínez, "Biculturalism unpacked: Components, individual differences, measurement, and outcomes," Social and Personality Psychology Compass, vol. 1, pp. 101-114, 2007.

[58] S. J. Schwartz and J. B. Unger, "Biculturalism and context: What is biculturalism, and when is it adaptive? Commentary on Mistry and Wu," Human Development, vol. 53, no. 1, pp. 26-32, 2010.

[59] D. Birman, "Biculturalism and ethnic identity: An integrated model," Focus, vol. 8, pp. 9-11, 1994.

[60] Q. L. Huynh, A. M. D. Nguyen, and V. Benet-Martínez, "Bicultural identity integration," in Handbook of Identity Theory and Research, S. J. Schwartz, K. Luyckx, and V. L. Vignoles, Eds., pp. 827-842, Springer, New York, NY, USA, 2011.

[61] M. B. Brewer, "Research design and issues of validity," in Handbook of Research Methods in Social and Personality Psychology, H. T. Reis and C. M. Judd, Eds., pp. 2-16, University Press, Cambridge, UK, 2000.

[62] B. Simon and D. Ruhs, "Identity and politicization among Turkish migrants in Germany: The role of dual identification," Journal of Personality and Social Psychology, vol. 95, no. 6, pp. 1354-1366, 2008.

[63] J. Skrobanek, Wahrgenommene Diskriminierung und (Re)Ethnisierung bei jugendlichen Zuwanderern [Perceived Discrimination and (Re-)Ethnicization in Adolescent Immigrants], Deutsches Jugendinstitut, Halle, Germany, 2007.

[64] D. L. Sam and E. Virta, "Intergenerational value discrepancies in immigrant and host-national families and their impact on psychological adaptation," Journal of Adolescence, vol. 26, no. 2, pp. 213-231, 2003.

[65] J. Kwast-Welfel, P. Boski, and M. Rovers, "Intergenerational value similarity in Polish immigrant families in Canada in comparison to intergenerational value similarity in Polish and Canadian non-immigrant families," in Perspectives and Progress in Contemporary Cross-Cultural Psychology, G. Zheng, K. Leung, and J. G. Adair, Eds., pp. 193-209, University of Ottawa, Ottawa, Canada, 2008.

[66] A. Knafo and S. H. Schwartz, "Value socialization in families of Israeli-born and Soviet-born adolescents in Israel," Journal of Cross-Cultural Psychology, vol. 32, no. 2, pp. 213-228, 2001.

[67] T. S. Kuhn, The Structure of Scientific Revolutions, The University of Chicago Press, Chicago, Ill, USA, 1962. 

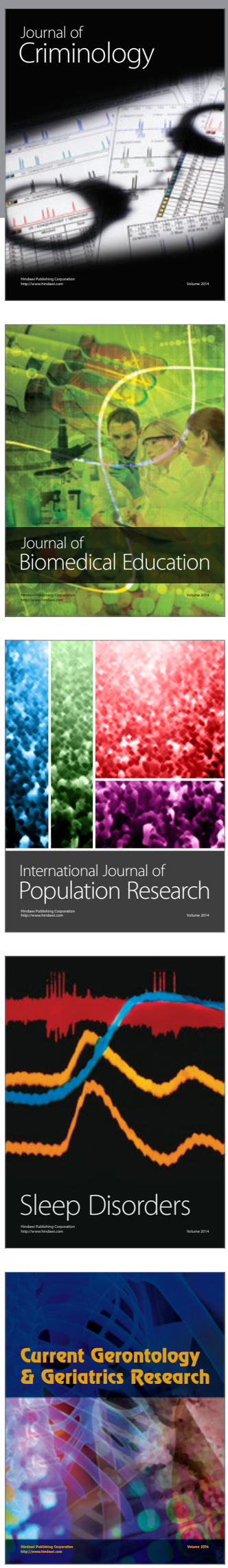
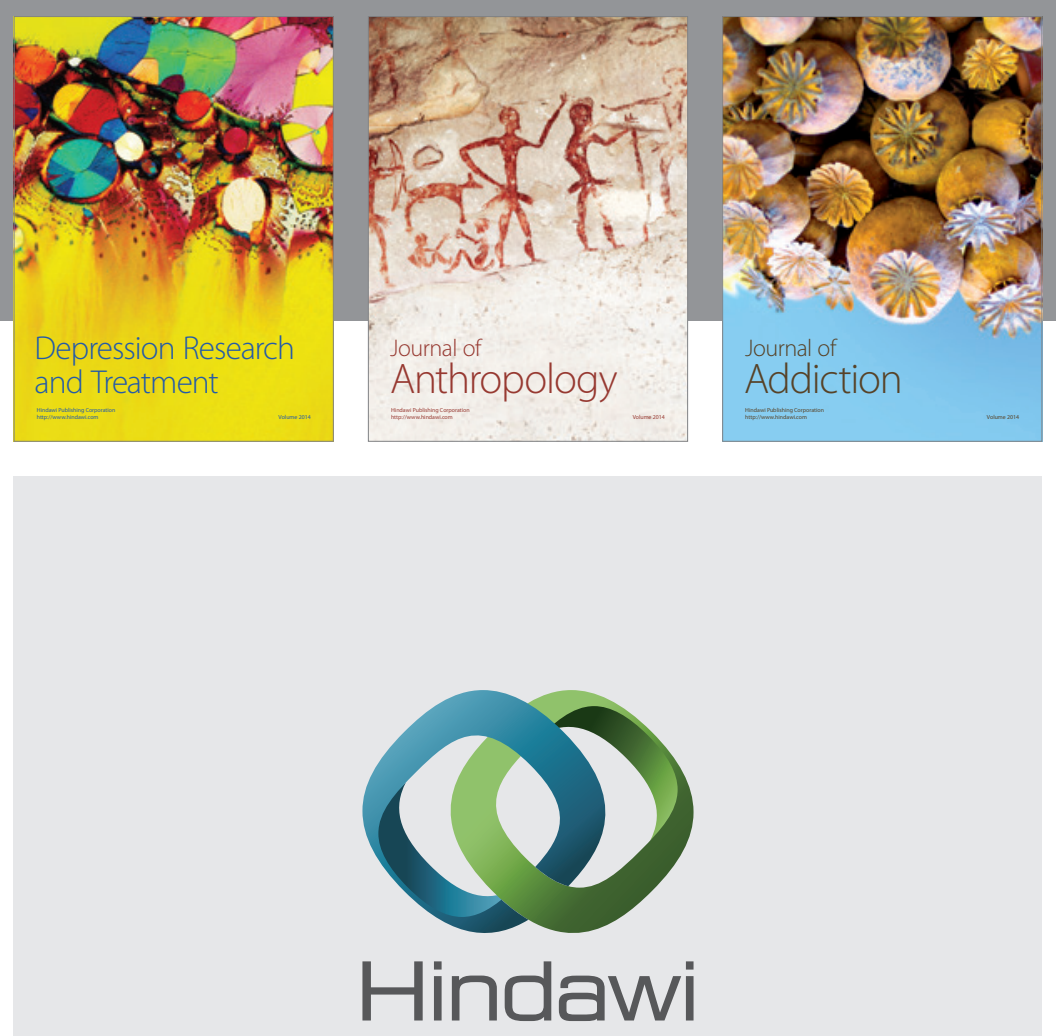

Submit your manuscripts at

http://www.hindawi.com

Child Development Research
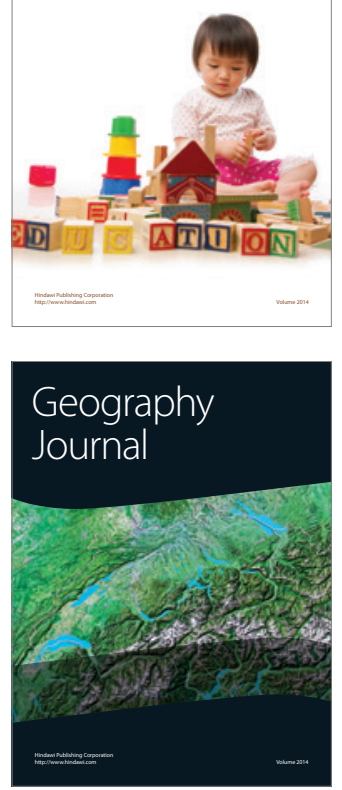

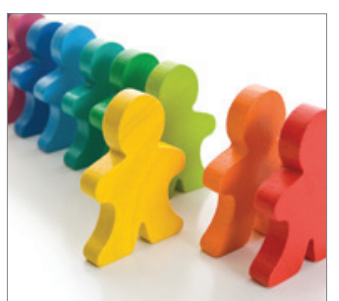

Autism

Research and Treatment
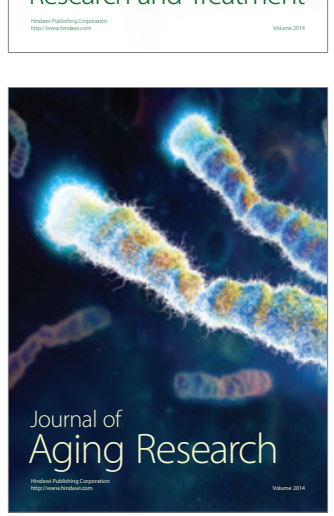
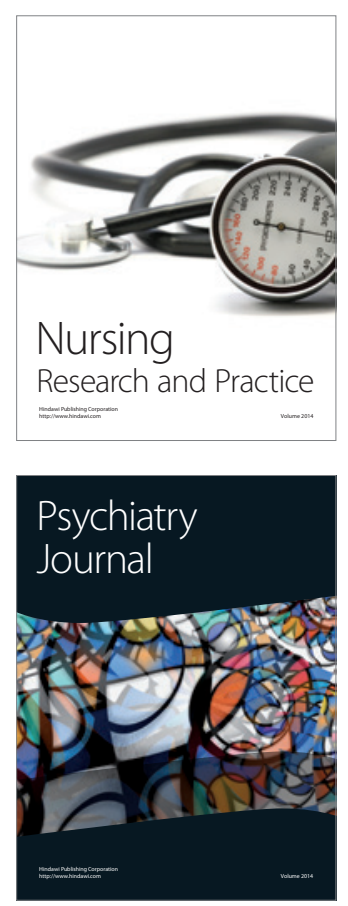
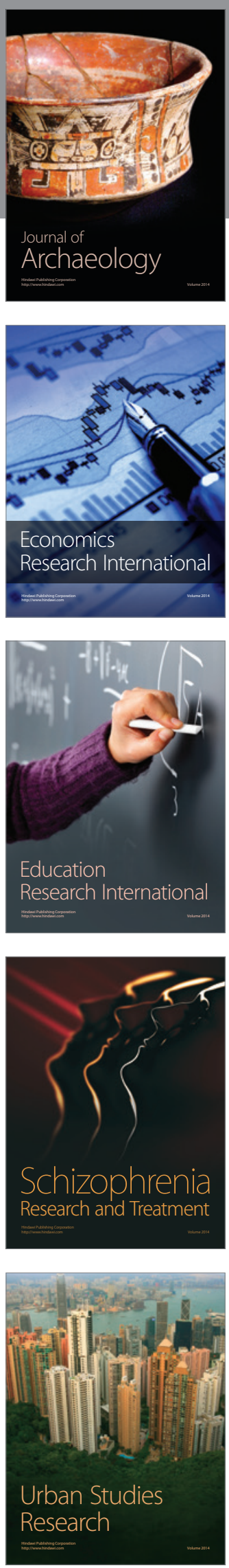